\title{
Bioethical issues in providing financial incentives to research participants
}

This article was published in the following Dove Press journal:

Medicolegal and Bioethics

24 June 2015

Number of times this article has been viewed

\section{David B Resnik}

National Institute of Environmental Health Sciences, National Institutes of Health, Research Triangle Park, NC, USA
Correspondence: David B Resnik National Institute of Environmental Health Sciences, National Institutes of Health, III Alexander Drive, Box 12233, Mail Drop CU 03, Research Triangle Park, NC, USA

$\mathrm{Tel}+|91954| 5658$

$\mathrm{Fax}+|91954| 9854$

Email resnikd@niehs.nih.gov

\begin{abstract}
Offering research subjects financial incentives for their participation is a common practice that boosts recruitment but also raises ethical concerns, such as undue inducement, exploitation, and biased enrollment. This article reviews the arguments for providing participants with financial incentives, ethical concerns about payment, and approaches to establishing appropriate compensation levels. It also makes recommendations for investigators, institutions, and oversight committees.
\end{abstract}

Keywords: human participant research, payment, ethics, undue inducement, exploitation, fairness

\section{Introduction}

Research subjects frequently receive financial compensation for their participation. ${ }^{1}$ The amount of payment varies considerably, depending on the type of research, the amount of time spent performing research activities, and the procedures involved in the research. ${ }^{2,3}$ For example, healthy subjects enrolled in a Phase I drug safety study typically receive several hundred to several thousand dollars for their participation, while subjects in social or behavioral research usually receive less than $\$ 50 .^{2}$ Subjects often receive a bonus for completing complex and lengthy studies, and payments are usually pro-rated in case subjects do not complete all of the research activities. ${ }^{2}$ The reasons typically given for paying research subjects include to boost recruitment and to compensate participants for their time and travel. ${ }^{4}$ Although paying research subjects is a common practice, it is ethically controversial. This article will review the ethical issues related to providing research participants with financial incentives.

\section{Arguments for paying research participants}

One of the main arguments for paying research participants is to boost recruitment. Research participation often involves the expenditure of considerable time and effort, and may involve pain, discomfort, inconvenience, and physical or psychosocial risks. While some subjects may decide to participate in research for altruistic reasons, many would not participate without financial incentives. Studies indicate that the offer of financial compensation is one of the main reasons why subjects participate in research. ${ }^{5-7}$ However, subjects often participate in research for non-financial reasons, such as to gain access to medical treatment or to contribute to the advancement of scientific knowledge or public health. ${ }^{7}$ The role of financial incentives in study recruitment depends on the nature of the research and the socioeconomic context. While financial 
incentives probably play a major role in encouraging healthy subjects to participate in Phase I drug safety studies in which participants receive no medical benefits, financial incentives probably play only a small role in encouraging patients to enroll in Phase II or III clinical trials in which participants receive treatment. ${ }^{7}$ Financial incentives probably play a more important role in recruitment for studies conducted in socioeconomically disadvantaged populations (such as populations in developing countries or impoverished regions of developed countries) than they do in studies conducted in well-to-do populations.

A second argument for paying human subjects for their participation is to provide them with a fair share of the benefits of research. ${ }^{8}$ One of the key principles of ethical research is that the benefits and risks of research should be distributed fairly. ${ }^{9}$ Participants who devote their time toward engaging in research activities and place themselves at risk deserve to receive some benefits in return. For some subjects, access to medical treatment may be sufficient recompense for their contribution to the research. For others, such as those participating in research involving no medical benefits, money may be a more appropriate form of compensation. ${ }^{10}$ Although guidance from regulatory agencies does not allow oversight committees, such as institutional review boards (IRBs), to treat money as a benefit when weighing the risks and benefits of research, most subjects consider money to be a personal benefit. ${ }^{11-13}$ Paying research subjects to provide them with a fair share of the benefits of research is consistent with the view that research participation is a type of paid labor (discussed below).

A third argument for paying research subjects is to provide them with a token of appreciation for their contribution to a study. ${ }^{1,9}$ Money is offered to thank subjects for their help. Expressing appreciation for someone's contribution to research helps to reinforce the trust that is essential to the relationship between investigators and subjects. Paying subjects is not the only way of showing appreciation, of course, since one may also show appreciation by giving subjects a gift, a gift card, or a thank you note. However, money is a form of appreciation that most people find suitable.

\section{Ethical concerns about paying participants Undue inducement}

Informed consent is one of the cornerstones of ethical research with human participants. ${ }^{9}$ Regulations and guidelines require that the research participant, or the participant's legal representative, provide consent to research, with a few exceptions. ${ }^{14-17}$
For consent to be valid, it should reflect the subject's (or representative's) autonomous choice to participate in research. Accordingly, regulations and guidelines also require that consent should take place under conditions that minimize the potential for coercion or undue inducement. ${ }^{16,17}$ One of the main ethical concerns about offering subjects money for their participation is that this could lead to coercion or undue inducement. ${ }^{1,17-20}$ Offering subjects money for their participation could undermine their autonomous decision-making by encouraging them to make financially motivated choices against their better judgment. ${ }^{1,20}$

To understand concerns about the influence of money on research participation decisions, it is useful to make an important distinction. Ethicists, IRB members, and lay people often characterize financial incentives as potentially coercive. ${ }^{21-23}$ However, this way of viewing financial incentives confuses the concepts of coercion and undue inducement. ${ }^{24-26}$ Coercion is the use of force, intimidation, or a threat to make someone comply with a demand or request. ${ }^{25} \mathrm{~A}$ coercive offer entails the threat of harm for failing to accept the offer. For example, if a clinical investigator told one of his patients that he will refuse to provide him with medical treatment unless he agrees to participate in a study, this would be a coercive offer, because the decision not to participate could result in harm to that person. However, the offer of money for research participation does not constitute coercion because it does not involve the threat of harm. ${ }^{26}$ Money is a benefit, not a harm. Thus, speaking of financial incentives as coercive is a conceptual mistake. ${ }^{26}$

Undue inducement is a better way of describing ethical concerns about the impact of money on informed consent for research participation. ${ }^{24}$ Undue inducement occurs when a person makes a choice in circumstances in which external factors are likely to have an inappropriate influence on his or her decision-making process. ${ }^{25}$ The choice made by the person is not entirely free because it is unduly influenced by these external factors. The typical situation involving undue inducement occurs when a person in a position of power or authority over another takes advantage of that person. For example, if a psychotherapist tries to establish a sexual relationship with one of her patients, this would constitute undue influence because she would be in a position of power over her patient. Undue inducement can occur in research without the offer of money.

Undue inducement related to financial incentives can be difficult to define, because most people accept the notion that it is appropriate to offer people money to perform tasks they probably would not perform without the offer of money ${ }^{26}$ 
For example, if you offer a plumber $\$ 200$ to fix your toilet, this would not constitute undue inducement, even though the offer of money would probably impact the plumber's decision to fix your toilet. Financial inducement is ethically acceptable, though undue inducement may not be. ${ }^{26}$

So what might make a financial inducement undue? One way of thinking about this issue is consider whether an offer of money is likely to cloud one's judgment, such that one's ability to make an informed choice is compromised. ${ }^{18,19}$ If a person is financially desperate or the offer of money is sufficiently large, then an offer of money might compromise that person's judgment and informed decision-making. For example, in the 1993 film "Indecent Proposal", David and Diana Murphy lose their life savings while gambling in Las Vegas. John Gage, a billionaire, offers the couple 1 million dollars if Diana will spend the night with him and have sex. One could argue that this offer of money constituted an undue influence over the couple's decision-making because they were so financially desperate that they could not think clearly about their decision. They fixated on the money they would receive and did not give adequate consideration to the consequences of accepting Gage's proposal. The million dollar offer impaired their judgment and decision-making.

Undue inducement could happen in research involving human subjects if prospective participants are strongly motivated by financial incentives, due to their circumstances or the amount of money offered. Prospective participants might make poor choices because money has clouded their judgment. ${ }^{18-20}$ They might be so swayed by an offer of money that they underestimate the risks and overestimate the benefits. The lure of money is especially difficult for socioeconomically disadvantaged individuals to resist. ${ }^{14,15,18-20}$ Some people rely on money derived from research participation as their main source of income. ${ }^{27}$ These "professional guinea pigs" might be willing to take ill-considered risks for the sake of money and some might falsify information requested by investigators to qualify for a study. ${ }^{27}$

While this argument has some plausibility, empirical research indicates that research subjects are probably not unduly influenced by modest financial incentives for participation. Several studies of healthy volunteers found that while money influences the decision to participate in research, it does not adversely impact judgments of risk. ${ }^{5,28-30}$ One study found that the level of payment is associated with the perception of risk: participants judged higher-paying studies to be riskier than lower-paying studies. Participants also spent more time learning about studies they perceived as high risk. ${ }^{31}$ A study of schizophrenic patients found that while money increased their willingness to participate in research, patients also formed independent judgments of risk and many were unwilling to participate in riskier studies, even for more money. ${ }^{32}$ Since only a few studies of the impact of financial incentives on informed consent for research participation have been conducted, more research is needed on this topic. It is important to know whether social, economic or psychological factors, such as income, education, culture, ethnicity, sex, nationality, or mental health status, have an impact on a person's susceptibility to financial inducement for research participation, since this information could be useful for establishing payment policies. ${ }^{33,34}$

Some have argued that the question of whether money impacts prospective subjects' judgments concerning risk is of little consequence, since oversight committees, such as IRBs, are charged with protecting human subjects from research risks. ${ }^{1,35,36}$ In the USA, IRBs are allowed to approve research involving human subjects only if they determine that the risks are minimized and reasonable in relation to the benefits to the participant or the value of the knowledge that may be gained. ${ }^{16}$ Those who are concerned about financial incentives for research participation argue that the lure of money might induce prospective subjects to take excessive risks against their better judgment. ${ }^{18-20}$ However, if an IRB has already reviewed a study, then it has evaluated these risks and determined that they are not excessive. The prospective subject's own judgment of risks has little impact on protecting him or her from research risks since the IRB has presumably done so.

While this argument makes a valid point, it does not prove that a prospective subject's judgments of risks are irrelevant to protecting him or her from harm. First, IRBs are not perfect. An IRB might approve a study without adequately evaluating the risks of the research. If this happens, then the prospective subject's own judgment could play an important role in protecting him or her from risks, since he or she could decide not to participate in a study that he or she views as too risky. Second, the IRB's evaluation of risks might be different from the subject's evaluation. An IRB might decide that the risks of a study are not excessive while some subjects might draw the opposite conclusion. People weigh risks and benefits differently and have different tolerances for risks. While the IRB's risk assessment plays an important role in protecting subjects from harm, the subject's own risk assessment also has some value. ${ }^{37}$ Subjects should not be induced to take risks that they are not comfortable with.

While concerns about undue inducement fail to prove that investigators should not offer prospective subjects financial 
rewards for participating in research, they do raise legitimate issues about the amount of money that participants should be offered. ${ }^{1}$ The amount of money offered should not be so large that it is likely to cloud the judgment of prospective participants. Approaches to establishing appropriate levels of financial incentives are discussed later in this review.

\section{Exploitation}

Another ethical concern related to paying human subjects for their participation in research is that offering subjects too little money could lead to exploitation. ${ }^{26}$ Exploitation involves taking unfair advantage of an individual or a group in a transaction or relationship. ${ }^{38}$ Exploitation can occur when both parties consent to a transaction or relationship and both benefit from it. Mutually beneficial exploitation occurs when the benefits of a transaction or relationship are distributed unfairly. For example, one might argue that some factory work conducted in developing countries is exploitative because the factory owners derive significant profits from the products made at the factory but pay their workers very low wages. ${ }^{38}$ One could argue that there is similar potential for exploitation in research involving human subjects if those who stand to benefit from studies, ie, sponsors, institutions, and investigators, do not offer participants a fair share of the economic benefits of research, ie, money. ${ }^{8,14,15}$ While offering subjects too much money could lead to undue inducement, offering them too little money could lead, paradoxically, to exploitation. ${ }^{1,8,26}$

Exploitation might also occur when children are offered money to participate in research, since parents might enroll their children in studies in order to reap financial rewards for themselves. ${ }^{1,39}$ Pediatric research payment practices vary widely. ${ }^{40}$ One survey found that payments to children range from $\$ 1$ to $\$ 1,000$, and children may be offered cash, gift cards, or saving bonds. ${ }^{41}$ To avoid parental exploitation of children, some have recommended that investigators should provide children with gifts but not money. ${ }^{42}$ Others have argued that payments for pediatric research are acceptable because parents need some compensation for the time they spend in taking their children to research activities. Payments should be large enough to reimburse parents for their travel and time, but not so large that they distort parental judgment. ${ }^{39}$

\section{Biased enrollment}

A third ethical concern with paying research participants is that this practice could lead to biased enrollment if it encourages individuals with a lower socioeconomic status (SES) to participate in research at a higher rate than individuals with a higher SES. ${ }^{14,15,19,26}$ The prospect of payment might have more of an impact on the decision to enroll in a study made by someone who is economically disadvantaged than it would on the decision made by someone who is well-to-do. As noted earlier, some individuals rely on the money from participation in research as their main form of income. These individuals might be more inclined to participate in research than people who do not need the money.

There are two problems with research enrollment that is biased with respect to participants' SES. The first is that biased enrollment could jeopardize the generalizability of research results. If a study lacks generalizability, then its scientific and social value may be diminished. One could argue that poorly designed scientific studies involving human participants are unethical because they unnecessarily expose people to risks. ${ }^{9}$ Although most studies seek to enroll participants from diverse races, ethnicities, and sexes, few have recruitment strategies that emphasize diversity with respect to SES. It is not known whether the SES of a study population impacts the generalizability of results, but it conceivably could, depending on the type of research being conducted. For example, biased enrollment with respect to SES could be a problem for a study that examines the role of socioeconomic factors in the response to treatment for depression.

The second problem is that biased enrollment could lead to a situation in which people of higher SES benefit from research conducted on people of lower SES. One could argue that this situation would be unfair, because the benefits and burdens of research would be distributed inequitably among different social classes. One could also argue that it would be exploitative, because high SES people would be taking unfair advantage of low SES people. ${ }^{14,19}$

It is difficult to assess concerns about biased enrollment because there are no published studies on how financial incentives impact the demographics of human participant research. If demographically biased enrollment occurs, it probably would have the most significant effect on studies involving healthy participants, since people from different social classes are likely to enroll in studies that offer medical benefits. Most diseases do not discriminate with respect to SES, eg, both rich and poor people develop cancer, hypertension, pneumonia, arthritis, and depression. Although wealthy people tend to have better access to health care than poor people, individuals from different social classes are likely to be motivated to participate in clinical trials in order to obtain access to new treatments. Since very little is known about how SES impacts research participation, more research is needed on this topic. 
One way of addressing the potential problem of biased enrollment, which this author does not recommend, would be to stratify payment according to income level: people with higher incomes would be offered more money to participate in research than those with lower incomes. The problems with this approach are obvious, as it would be unfair to pay people different amounts of money for performing the same activities. There should be equal pay for equal work. This approach could also lead to exploitation if poor people are not paid enough money for their participation.

It is important to note that not paying research subjects may bias a study population toward participants with higher SES, since these participants may be able to afford to participate in research without financial compensation. Since health is positively associated with SES, this sort of bias could be a major concern in research that examines the relationship between health outcomes and medical interventions, genetic or genomic factors, or environmental exposures.

\section{Establishing an appropriate level of payment}

There are several different approaches to establishing an appropriate amount of payment for research participation. According to the free market approach, participants should be paid based on principles of supply and demand. ${ }^{1,10}$ Prospective participants should be offered enough money to meet recruitment goals. Payments could be adjusted, higher or lower, depending on the amount of money that is needed to motivate individuals to participate in research. Payments could be pro-rated if participants do not complete all study activities, and bonuses could be given to participants who complete all study requirements. One of the advantages of this approach is that it explicitly recognizes that research participation is a form of paid labor. ${ }^{15}$ Thinking of human subjects as workers encourage sponsors and institutions not only to pay subjects what they are worth, but also to compensate them for research-related injuries. ${ }^{15,42}$ An ethical problem with this approach is that it could lead to undue inducement if subjects are paid too much or exploitation if they are paid too little..$^{1,10}$

According to the appreciation approach, participants should be paid only a nominal amount of money as an expression of gratitude for their contribution to research. ${ }^{1,10}$ The appreciation approach characterizes research participation as a type of altruism, not as a type of paid labor. One problem with this approach is that it would seem to not apply to projects such as Phase I studies of new drugs in healthy subjects, in which the main motivation for participation is to earn money. Participants in a study that involves the ingestion of an experimental drug, a 2-day stay in hospital, and dozens of laboratory tests expect and deserve more for their time and inconvenience than a token amount of payment. Adopting the appreciation approach could also result in underpayment of participants and lead to problems with recruitment. ${ }^{1,10}$

According to the reimbursement approach, participants should be reimbursed for actual expenses, such as travel and lost wages. ${ }^{1,10}$ An advantage of this approach is that it would establish clear guidelines for payment, since subjects could submit receipts or check stubs to receive reimbursement. An ethical problem with the reimbursement approach is that participants might receive radically different payments for the same study, since people might have jobs that pay differently. ${ }^{1,10}$ As noted above, one could argue that paying participants different amounts of money for the same activities is inherently unfair.

According to the wage-payment approach, participants should be paid a standard hourly wage roughly equivalent to the amount of money one would earn for unskilled labor (approximately $\$ 10$ per hour in the USA). Participants could receive additional money to compensate them for travel or inconvenience. ${ }^{1,10}$ One of the advantages of the wage-payment model is that it establishes clear payment guidelines that probably will not lead to undue inducement or underpayment. A disadvantage of this approach is that it might lead to recruitment problems if wages are not set high enough. Furthermore, one might argue that fairness demands that subjects should be paid more money for studies that involve risky or painful procedures. For example, one might argue that a participant who is receiving a bronchoscopy for a study should be paid more than a participant who is completing a survey, even if both studies involve the same amount of time.

Since each of these approaches have advantages and disadvantages, the best way of establishing an appropriate level of payment may be to use some combination of these different approaches, depending on the type of research being conducted. For example, a Phase I drug safety study in healthy volunteers could pay them a standard wage for their time, with additional money to compensate them for pain, discomfort, inconvenience, risk exposure, and travel costs. A Phase II clinical trial in pediatric patients could offer the participants a gift or gift card as an appreciation for their contribution and provide the parents with compensation for travel costs.

\section{Conclusion}

Offering research subjects financial incentives for their participation is a common practice that boosts recruitment 
but also raises ethical concerns, such as undue inducement, exploitation, and biased enrollment. Investigators and oversight committees should work together to establish appropriate financial incentives for research participants. When determining an appropriate level of payment, investigators and oversight committees should consider: the amount of time participants spend on research activities; the risk, pain, discomfort, and inconvenience associated with research procedures; travel costs; recruitment issues; and the characteristics of the study population (eg, income, age, and mental health status). Institutions and oversight committees should consider developing policies pertaining to financial incentives for research participants. To ensure consistent guidance, such policies could establish standard payments for different types of studies and procedures. ${ }^{43,44}$

\section{Acknowledgment}

This research is supported by the National Institute of Environmental Health Sciences, National Institutes of Health. It does not represent the views of the National Institute of Environmental Health Sciences, the National Institutes of Health, or the US government.

\section{Disclosure}

The author reports no conflicts of interest in this work.

\section{References}

1. Grady C. Payment of clinical research subjects. J Clin Invest. 2005; 115(7):1681-1687.

2. Grady C, Dickert N, Jawetz T, Gensler G, Emanuel E. An analysis of US practices of paying research participants. Contemp Clin Trials. 2005;26(3):365-375.

3. Fry CL, Ritter A, Baldwin S, et al. Paying research participants: a study of current practices in Australia. J Med Ethics. 2005;31(9): 542-547.

4. Ripley E, Macrina F, Markowitz M, Gennings C. Why do we pay? A national survey of investigators and IRB chairpersons. J Empir Res Hum Res Ethics. 2010;5(3):43-56.

5. Bentley JP, Thacker PG. The influence of risk and monetary payment on the research participation decision making process. $J$ Med Ethics. 2004;30(3):293-298.

6. Tishler CL, Bartholomae S. The recruitment of normal healthy volunteers: a review of the literature on the use of financial incentives. J Clin Pharmacol. 2002;42(4):365-375.

7. Stunkel L, Grady C. More than the money: a review of the literature examining healthy volunteer motivations. Contemp Clin Trials. 2011;32(3):342-352.

8. Shamoo A, Resnik DB. Strategies to minimize risks and exploitation in phase one trials on healthy subjects. Am J Bioethics. 2006;6(3): W1-W13.

9. Emanuel EJ, Wendler D, Grady C. What makes clinical research ethical? JAMA. 2000;283(20):2701-2711.

10. Dickert N, Grady C. What's the price of a research subject? Approaches to payment for research participation. N Engl J Med. 1999;341(3): 198-203.

11. Wertheimer A. Is payment a benefit? Bioethics. 2013;27(2):105-116.
12. Czarny MJ, Kass NE, Flexner C, Carson KA, Myers RK, Fuchs EJ. Payment to healthy volunteers in clinical research: the research subject's perspective. Clin Pharmacol Ther. 2010;87(3):286-293.

13. Breitkopf CR, Loza M, Vincent K, Moench T, Stanberry LR, Rosenthal SL. Perceptions of reimbursement for clinical trial participation. J Empir Res Hum Res Ethics. 2011;6(3):31-38.

14. Elliott $\mathrm{C}$, Abadie R. Exploiting a research underclass in phase 1 clinical trials. $N$ Engl J Med. 2008;358(22):2316-2317.

15. Lemmens T, Elliott C. Guinea pigs on the payroll: the ethics of paying research subjects. Account Res. 1999;7(1):3-20.

16. Department of Health and Human Services. Protection of Human Subjects. 45 CFR 46, 2009. Available from: http://www.hhs.gov/ohrp/ policy/ohrpregulations.pdf. Accessed June 3, 2015.

17. Council for the International Organizations of Medical Sciences. International ethical guidelines for biomedical research involving human subjects. Available from: http://www.cioms.ch/publications/guidelines/ guidelines_nov_2002_blurb.htm. Accessed December 17, 2014.

18. Macklin R. On paying money to research subjects: 'due' and 'undue' inducements. IRB. 1981;3(5):1-6.

19. Faden R, Beauchamp T. A History and Theory of Informed Consent. New York, NY, USA: Oxford University Press; 1986.

20. McNeill P. Paying people to participate in research: why not? A response to Wilkinson and Moore. Bioethics. 1997;11(5):390-396.

21. Largent E, Grady C, Miller FG, Wertheimer A. Misconceptions about coercion and undue influence: reflections on the views of IRB members. Bioethics. 2013;27(9):500-507.

22. Largent EA, Grady C, Miller FG, Wertheimer A. Money, coercion, and undue inducement: attitudes about payments to research participants. IRB. 2012;34(1):1-8.

23. Klitzman R. How IRBs view and make decisions about coercion and undue influence. J Med Ethics. 2013;39(4):224-229.

24. Grady C. Money for research participation: does in jeopardize informed consent? 1. Am J Bioeth. 2001;1(2):40-44.

25. Wertheimer A, Miller FG. Payment for research participation: a coercive offer? J Med Ethics. 2008;34(5):389-392.

26. Wilkinson M, Moore A. Inducement in research. Bioethics. 1997;11(5): 373-389.

27. Abadie R. The Professional Guinea Pig: Big Pharma and the Risky World of Human Subjects. Durham, NC, USA: Duke University Press; 2010.

28. Halpern SD, Karlawish JH, Casarett D, Berlin JA, Asch DA. Empirical assessment of whether moderate payments are undue or unjust inducements for participation in clinical trials. Arch Intern Med. 2004;164(7): 801-803.

29. Singer E, Couper MP. Do incentives exert undue influence on survey participation? Experimental evidence. J Empir Res Hum Res Ethics. 2008;3(3):49-56.

30. Mantzari E, Vogt F, Marteau TM. Does incentivising pill-taking 'crowd out' risk-information processing? Evidence from a web-based experiment. Soc Sci Med. 2014;106:75-82.

31. Cryder CE, London JA, Volpp KG, Loewenstein G. Informative inducement: study payment as a signal of risk. Soc Sci Med. 2010;70(3): 455-464.

32. Dunn LB, Kim DS, Fellows IE, Palmer BW. Worth the risk? Relationship of incentives to risk and benefit perceptions and willingness to participate in schizophrenia research. Schizophr Bull. 2009;35(4):730-737.

33. Klitzman R. The importance of social, cultural, and economic contexts, and empirical research in examining "undue inducement". Am J Bioeth. 2005;5(5):19-21.

34. Emanuel EJ, Currie XE, Herman A; Project Phidisa. Undue inducement in clinical research in developing countries: is it a worry? Lancet. 2005; 366(9482):336-340.

35. Emanuel EJ. Ending concerns about undue inducement. $J$ Law Med Ethics. 2004;32(1):100-105.

36. Emanuel EJ. Undue inducement: nonsense on stilts? Am J Bioeth. 2005; 5(5):9-13. 
37. London AJ. Undue inducements and reasonable risks: will the dismal science lead to dismal research ethics? Am J Bioeth. 2005;5(5):29-32.

38. Wertheimer A. Exploitation. Princeton, NJ, USA: Princeton University Press; 1999.

39. Wendler D, Rackoff JE, Emanuel EJ, Grady C. The ethics of paying for children's participation in research. J Pediatr. 2002;141(2): 166-171.

40. Iltis AS, DeVader S, Matsuo H. Payments to children and adolescents enrolled in research: a pilot study. Pediatrics. 2006;118(4): 1546-1552.
41. Weise KL, Smith ML, Maschke KJ, Copeland HL. National practices regarding payment to research subjects for participating in pediatric research. Pediatrics. 2002;110(3):577-582.

42. [No authors listed]. Guidelines for the ethical conduct of studies to evaluate drugs in pediatric populations. Committee on Drugs, American Academy of Pediatrics. Pediatrics. 1995;95(2):286-294.

43. Lemmens T, Miller PB. Regulating the market in human research participants. PLoS Med. 2006;3(8):e330.

44. Dickert N, Emanuel E, Grady C. Paying research subjects: an analysis of current policies. Ann Intern Med. 2002;136(5):368-373.

\section{Publish your work in this journal}

Medicolegal and Bioethics is an international, peer-reviewed, open access journal exploring the application of law to medical and drug research and practice and the related ethical and moral considerations. The journal is characterized by the rapid reporting of reviews, case reports, guidelines and consensus statements, original research

\section{Dovepress}

and surveys. The manuscript management system is completely online and includes a very quick and fair peer-review system. Visit http://www.dovepress.com/testimonials.php to read real quotes from published authors.

\footnotetext{
Submit your manuscript here: http://www.dovepress.com/medicolegal-and-bioethics-journal
} 